\title{
UM PREFÁCIO À BIOGRAFIA
}

André Luis M itidieri $^{1}$

Resumo: 0 presente artigo discorre sobre antigas espécies biográficas, em suas interconexões com a poética, a retórica, a filosofia e a história. Associadas aos conceitos de "memória", "rememoração", "imagem", "mimese" e "testemunho", as primeiras formas aparentadas à biografia, de que se tem notícia no mundo ocidental, configuravam-se em paralelo à decadência da pólis grega. Nesse contexto, o homem público não teria condições de estabelecer diferenças entre a própria vida e vidas outras, de maneira que a separação entre 0 autobiográfico e o biográfico apenas ocorreria depois que tal unidade viesse a desintegrar-se.

Palavras-Chave: Biografia, Memória, M imese, Testemunho.

Resumen: Este artículo trata de las antiguas espécies biográficas, en sus interconexiones con la poética, la retórica, la filosofía y la historia. Vinculadas a los conceptos de "memoria", "rememoración", "imagen", "mimesis" y "testimonio", las primeras formas asemejadas com la biografía, de las cuales hay conocimiento en el mundo ocidental, se han configurado al mismo tiempo em que ocurria el declinio de la pólis griega. En ese contexto, el hombre público no tendría condições de apartar la própia vida de vidas ajenas, de modo que la separación entre el autobiográfico y lo biográfico solamente habría de ocurrir luego que tal unidade se desintegrara.

Palabras-Clave: Biografía, M emoria, Mimesis, Testimonio.

A palavra "biografia" tem origem etimológica nos vocábulos gregos Bios (vida) e Gráphein (desenhar, gravar, ou a ação de escrever, descrição, tratado ou estudo). Partindo desse pressuposto, uma espécie biográfica se faria suportar pela escrita, por descrições orais e até mesmo por imagens. 0 conceito expresso por "grafia", também presente em "historiografia", suscita uma pergunta inicial: vidas ou histórias podem ser escritas, desenhadas, gravadas em algum lugar?

Para respondê-la, faz-se necessário lembrar que fontes remotas duma arte biográfica encontram-se nos relatos dedicados a patriarcas e reis de Israel (Antigo Testamento), bem como aos heróis épicos de sagas gregas, germânicas e célticas. Outro tipo biográfico despontava nos ensinamentos de santos e sábios, constantes nos livros proféticos da Bíblia. De modo semelhante, nas

1 Doutor pela Pontifícia Universidade Católica do Rio Grande do Sul (PUC-RS); Professor Adjunto de Língua e Literatura Espanhola na Universidade Estadual de Santa Cruz (UESC); Docente Colaborador junto ao Programa de Pós-Graduação em Letras, da URI, Campus Frederico Westphalen; endereço eletrônico: mitidierister@gmail.com. 
sentenças de Buda; nos fragmentos antológicos de Confúcio e nas palavras dos Sete Sábios da Grécia².

No Ocidente, as espécies que se assemelham às narrativas biográficas remontam à era clássica dos gregos (séc. V-IV a.C.). Além dos fragmentos com teor biográfico, os helenos puderam conservar alguns resíduos de mitos aqueus e das epopéias do período arcaico (VIII-V a.C.). Articuladas, linguagem e memória haviam permitido a circulação oral dessas histórias, até que 0 alfabeto se revelasse um importante aliado contra o esquecimento e o risco da efemeridade, próprio à memória.

Substituindo as faculdades de memorização, a escrita se conecta nem tão somente à história da poética ocidental, mas também às histórias da filosofia e da própria historiografia. As primeiras escritas conjugaram uma contabilidade elementar com o sistema de representações míticas e se viabilizaram em paralelo ao desenvolvimento da metalurgia e dos agrupamentos humanos. A descontinuidade entre o meio pensado e o ser pensante acontecia junto à fixação agrícola: "O seu fundamento está na criação de uma imagem cósmica cujo pivot é a cidade" (LEROI-GOURHAN, 1985, p. 210. v. 1).

Os poemas épicos sinalizam a certa articulação dos velhos modos de falar; sua transcrição, paralela ao nascimento do alfabeto, revela a capacidade dos textos homéricos em transmitir suas narrativas sob condições ainda préletradas. A mimese homérica, entretanto, não tentava copiar da aparência; igual ao mito, vinha das "figuras inteiriças" cuja unidade já existia antes da observação de que se faziam objeto. "Sua presença viva e sua diversidade provêm, como é possível perceber por toda parte, da situação em que inevitavelmente elas se vêem envolvidas; e é essa situação que determina suas ações e seus procedimentos" (AUERBACH, 1997, p. 14-15).

Originalmente, a palavra grega My̆thos designava qualquer narração, ficcional ou que se ligasse a eventos reais, para depois exprimir narrativas de ordem lendária ou maravilhosa. Assim, os mitos reunidos na Teogonia (1979) e n'Os trabalhos e os dias (1996) indicam que Hesíodo (séc. VIII a.C.) pareceu compreender a necessidade de unificar o conjunto humano, confrontando-o com a ordenação do $\operatorname{cosmos}^{3}$. 0 registro mítico e a poesia épica, bem como os

2 M uitas histórias da Bíblia centraram-se na narração biográfica: Noé e sua arca; Moisés, José, João Batista, os reis magos; Davi e Golias, Sansão e Dalila; Josué, o homem que fez parar o Sol; Daniel na cova dos leões. Não por acaso, personagens e temas bíblicos foram retomados em várias obras da literatura ocidental, como José e seus irmãos, por Thomas M ann, Esaú e Jacó, por Machado de Assis, Jacó e Raquel, por Camões. Cf. BIOGRAPHY, 1990; M ACHADO, 2002, p. 40.

A llíada e a Odisséia já são construções complexas, indicando o começo de uma parceria fecunda entre o oral e o escrito. Cf. HAVELOCK, 1996b, p. 16. 
universais poéticos que vieram depois deles - drama e lírica - sofreram os efeitos da tensão entre as modalidades orais e escritas da linguagem.

Isso não constitui um elemento isolado de outras tensões: em percurso jamais cumprido sobre uma linha reta nem constante, a civilização helênica enfrentava longo processo de modificações políticas, religiosas e sociais. A sistematização dos métodos de escrever proporcionava uma das condições para que os gregos se enamorassem de Sophía, quer dizer, da sabedoria. Os gregos principiaram lentamente a desenvolver-se conforme os modos de pensamento lógico e analítico, encaminhando-se à filosofia, entre os séculos IX e VI a.C.

Arquíloco de Paros (c. 680-646 a.C.) criticava o ideal heróico, rechaçava o mito e expunha seu desejo de inscrever-se no político. Para Max Treu (1955), a doutrina da mímesis fora testemunhada ineditamente pelo arcaico poeta, em sua expressão "A palavra é a imagem da realidade." Arquíloco descerrou caminhos para uma grande ruptura na arte poética dos helenos, que Simônides de Céos (c. 556-c. 467 a.C.) teria o mérito de assinalar, ao praticá-la como um ofício e ao defini-la como um produto ilusório.

Esse fabricador de epigramas responsabilizou-se por secularizar a poesia e descobrir a técnica de memorização. A memória se transformava em faculdade psicológica e cada pessoa iria desempenhá-la segundo normas, de um ou de outro jeito, previamente definidas, entretanto, "postas ao alcance de todos. A invenção da mnemotécnica corresponde à mesma intenção de um outro aperfeiçoamento técnico, atribuído a Simônides: a invenção de letras do alfabeto que deviam permitir uma melhor notação escrita" (DETIENNE, 1988, p. 57).

0 "lírico de Céos" $^{4}$ relacionou a memória com uma noção inovadora que, por sua vez, associava o tempo à aprendizagem e se desvinculava da idéia divina de Chrónos (PAGE, 2003, p. 521-527). Ao assinalar uma atividade profana, Simônides rompeu com a tradição anterior - da "palavra inspirada" num quadro bem definido econômica e socioculturalmente: 0 da pólis. A cidade mais a retórica se faziam acompanhar do desenvolvimento da escrita, assim

4 Seria notável que os poetas não mais recorressem à "simples recitação, para apresentarem suas obras. Desde o século VII a escrita é a forma necessária de publicação" (DETIENNE, 1988, p. 57). Porém, o termo lírico, "tal como hoje se usa, é pós-clássico, e se emprega, freqüentemente, para identificar as fragmentárias relíquias de uma série de poetas entre Arquíloco e Simônides. Em seu próprio tempo, esses poetas [líricos] não eram lidos, mas ouvidos. Para alcançar, em qualquer medida, o que chamamos de 'publicação', suas 'obras' deviam ser, não escritas, mas executadas, perante audiências grandes ou pequenas" (HAVELOCK, 1996b, p. 26). 
também, a poesia, embora sua forma épica antes houvesse transitado pela oralidade.

Os "filósofos da natureza" já conduziam sua reflexão sobre o lógos, príncípio de toda inteligibidade, no século VI a.C. Todavia, os "filosofadores" ${ }^{5}$ présocráticos pensavam a palavra como um caminho de reconhecimento do real ${ }^{6}$. A configuração urbana se dava em meio à crise que destituiu a Hélade duma "presença obsessiva do monarca minóico ou micênico, êmulo dos 'déspotas' orientais. Mas, antes da razão, está aquilo que a fundamenta, ou seja, a representação que o homem faz, no caso, o homem grego, da verdade, Alétheia" (VIDAL-NAQUET, 1988, p. 8).

Nascida na Magna Grécia, a retórica somou forças com aquele protopensamento racional do século VI a.C. De igual maneira, viria confluir com a sofística, que se organizava durante a próxima centúria, no interior de semeIhante moldura: encravada numa rudimentar democracia e nos primeiros movimentos da justiça exercida sob forma dialogal. Os sofistas propunham-se a uma educação instituída pelo discurso e voltada à práxis dentro das urbes helênicas.

Aliados à filosofia socrática, eles unificaram ética e política, reconhecendo-as como um tópico discursivo inseparável. A história, que designava um conceito jurídico do "verdadeiro", seguia o mesmo compasso da tecnologia alfabética. 0 historiador também sentiria os efeitos da laicização da memória e da palavra (CHÂTELET, 1985). A raiz de tais vocábulos assenta-se na Grécia dos tempos arcaicos, onde o hístor era uma testemunha:

aquele que vê e que escuta, e, na sua qualidade de herdeiro do mnémon, é também um memorialista. Em sua 'verdade', atestam-se, pelo menos, duas componentes: o não-esquecimento e, complementarmente, o relato exaustivo, o relato completo, exaustivo, o relato daquilo que aconteceu realmente (DETIENNE, 1988, p. 119).

5 O substantivo "filósofo" não consta em documentos escritos antes do último quartel do século $\mathrm{V}$ a.C. Os pré-socráticos tiveram que descobrir o pensamento conceitual como idéia e método antes de surgirem os produtos do pensamento, isto é, os sistemas. Abrangem de Xenófanes a Demócrito, mas a chamada Escola de Mileto não pode ser incluída porque, no direcionamento da mente grega ao abstrato, "qualquer contribuição que possam ter feito se perdeu. Todas as suas ipsissima verba desapareceram e com elas qualquer indício de tentativas conceituais" (HAVELOCK, 1996a, p. 315).

6

0 real "é compreendido como o mundo extratextual, que, enquanto faticidade, é prévio ao texto e que ordinariamente constitui seus campos de referência. Estes podem ser sistemas de sentido, sistemas sociais e imagens do mundo, assim como podem ser, por exemplo, outros textos, em que se efetua uma organização específica, ou seja, uma interpretação da realidade. Em conseqüência, o real se determina como o múltiplo dos discursos, a que se refere 0 acesso ao mundo do autor, tal como mostrado pelo texto" (ISER, 1983, p. 412-413).

A Cor das Letras - UEFS, n. 10, 2009 
0 alfabeto vocálico sofria pequenas mudanças e a alfabetização se tornava comum entre a quinta e a quarta centúrias a.C. Depondo a favor da disseminação do letramento, as "artes" retórica e poética encorpavam-se como áreas de estudo ${ }^{7}$. A retórica se caracterizou por tratar basicamente da oratória e do raciocínio, enquanto a poética veio-se ocupando dos tipos épico e mítico da poesia; mais tarde, do drama e da lírica propriamente dita. Marcas da retórica sofística e, de certa forma, da tematização biográfica, pronunciam-se no Elogio a Helena (414 a.C.), discurso elaborado pelo sofista Górgias (c. 485/480375 a.C.).

Sócrates (c. 469-399 a.C.) tangenciaria o ingresso da "ficção" na memória, conforme os diálogos platônicos M ênon e Teeteto (427 a.C.-348/347 a.C.). Através do conceito de Anamnese (reminiscência) e baseado na "metempsicose" (transmigração das almas), Platão inaugurou a teoria do conhecimento, desenvolvida em Fedro, Banquete, Fédon e A República. Em suas reflexões, 0 invento da escrita acarretaria o fim do ato de recordar - que acessava o conhecimento do "verdadeiro" - pois a rememoração impressa em letras aparecia como renovado mecanismo, apto a repetir as formas da vocalidade (SM OLKA, p. 174, 2000) $)^{8}$.

A cultura helênica teria dependido da memória doutrinadora, a qual se interligava com uma identificação entre artista e público. Acontecendo durante a reencenação dos poemas, o elo condenado pelo filósofo de Atenas - entre platéia e declamador - constituiria um ato e um estado "mimético". No entanto, "a raison d'être do seu ataque é que, na execução poética, como era praticada até então na Grécia, não havia um 'original'. 0 termo mímesis é escolhido por Platão como o único perfeitamente adequado" (HAVELOCK, 1996a, p. 177$)^{9}$.

7 Não quer dizer que a poética e a retórica já existissem como sólidos campos "do discurso e do conhecimento, mas coube a Sócrates e aos sofistas unificá-los como campos e reconhecêlos como tópicos, a fim de preparar o caminho para que se tornassem disciplinas" (HAVELOCK, 1996a, p. 315).

Estas palavras relacionavam-se com Ápate (engano) quando a filosofia empenhou-se para substituir o discurso figurativo pelo conceitual: Eikōn (signo e presença duma coisa ausente); Eidólon (o acontecimento representado e ausente). Nas reflexões platônicas, ambas envolvem a problemática da imaginação, que compreenderia também a da memória, e admitem as respectivas traduções: cópia com idéia de fiel semelhança; imagem do evento copiado. Cf. RICOEUR, 2004, p. 20-33.

9 A mímesis veio equivalendo ao conceito tradicional de representação, embora não se confundisse com uma cópia. Seu objeto, "mimema, importa enquanto ilustra uma determinada visão de mundo; a arte causa o regozijo do filósofo e do intérprete ao confirmar a justeza de 
Aristóteles (384-322 a.C.) retomava fundamentos platônicos a respeito da memória (Mnēmē), todavia, separou-a da rememoração (Anamnēssi). No livro I de sua obra Metafísica (1979, p. 8-35), o filósofo de Estagira declara que a primeira conservaria o passado, equivalendo à lembrança das sensações percebidas e imaginadas, ao passo que a segunda consistiria no ato de convocar as impressões sensoriais, através da vontade. Um estímulo sentido pelo ser humano produziria forma analógica à sensação experimentada, vinculando as coisas de que se recorda ao recebimento por meio dos sentidos.

Conforme o estagirita (1994, p. 281-304), a memória equivale a uma qualidade (afeto) do sensível ou do julgado. As rememorações devem-se a tal estado sensório, indutor de suas existências, no tempo decorrido entre o retorno do elemento afetivo e sua primeira impressão na alma, como "imagem". A problemática da imagem na lembrança era trazida pela distinção aristotélica entre os termos Phantasma (a inscrição mesma, um desenho, um quadro etc.) e Eikōn (a representação de algo diverso).

Os elos da memória com a imaginação, as recordações e a distância temporal ainda exigiram a definição de Mnēmoneuma. Esse vocábulo significava uma lembrança, um souvenir, já que faria pensar em algo distinto de sua própria constituição. Integrando a parte do espírito que deveria interseccionarse com os mecanismos imaginativos, a memória era conferida ao passado e a imagem, distanciada duma simples acepção de cópia, o que não eliminava uma "aporia da presença da ausência" (KRELL, 1990; RICOEUR, 2004, p. 33-41).

Ao supor a experiência como necessária à realização dos artefatos culturais, Aristóteles fica mais próximo ao reconhecimento dos universos da ficção. Quando se reconhece um ato de fingir nas estruturas ou nos elementos de um texto, "os critérios naturais quanto a este mundo representado estão suspensos. Assim, nem o mundo representado retorna por efeito de si mesmo, nem se esgota na descrição de um mundo que Ihe seria pré-dado. Estes critérios naturais são postos entre parênteses pelo como se" (ISER, 1983, p. 400).

No século em que viveram os filósofos de Atenas e Estagira, Grammatikós passou a fazer parte do vocabulário grego; nomeava os aptos a ler, tomando lugar ao termo precedente: Kritikós. Na mesma centúria, um tipo de ancestral do papel, manufaturado a partir da planta do Cyperus Papirus, expandiu-se desde 0 Egito e daria nova forma de disposição aos antigos textos. A inovadora

suas idéias. Assim o não entendimento da mimesis correspondia a uma hierarquia implícita: em primeiro plano, apontava o discurso conceitual, o que diz o que é e separa a verdade das opiniões, seja ele identificado com o discurso filosófico ou com o científico. É ele então que disciplina os discursos inferiores, que carecem de sua incidência para que se digam valorizáveis ou desprezíveis" (COSTA UMA, 1981, p. 227). 
técnica do papiro, lado a lado com a descoberta de outros suportes, proporcionariam terrenos mais amplos à secularização da memória e da palavra.

A decadência da pólis jogava papel essencial à ampliação das espécies biográficas, que se tornariam mais relevantes quando a ruína da sociedade urbana produzisse uma idéia de generalizado desencanto. A biografia ocidental ia surgindo enquanto se alterava o status dos gregos, ou seja, durante a "ruptura havida entre a civilização da pólis e os grandes impérios que se lhe seguem. Na crise, impõe-se a necessidade do registro, cujo 'balizamento' são vidas que se relatam" (CARINO, p. 160, 1999).

Os caminhos abertos ao espaço biográfico não deixavam de vincular 0 cidadão aos domínios da ágora. Ao se pronunciar, o homem público nem podia fazer diferenciações entre a própria existência e a vida alheia: a separação entre biografia e autobiografia só iria ocorrer depois que essa unidade se desintegrasse. Suas formas clássicas não eram "desligadas do acontecimento político social e concreto, e de sua publicidade retumbante. Ao contrário, elas eram inteiramente definidas por esse acontecimento; eram atos verbais cívicopolíticos, de glorificação ou de autojustificação públicas" (BAKHTIN, 1990, p. 251).

Em lugar de sete sábios gregos, foi Sophía quem, ao se recolher na escrita, passou a transmitir o mito, a poesia, retórica, sofística, filosofia, história e, ainda, o discurso ético-político. Entravada no pretérito arcaico, a Paideía de Homero fez-se advertência, lembrança, memorização e se faria reminiscência, rememoração ou retorno do reprimido. Como a musa, de canto sedutor, os saberes ocidentais aqui fluem desde o leito de $M$ némosine, a mãe das musas. M emória encarnada, ela ajuda na identificação das barreiras por cujo intermédio se pode combater as ações erosivas de Améles, o rio do esquecimento.

\section{REFERÊNCIAS}

ARISTÓTELES. M etafísica, livro I. In ARISTÓTELES. Aristóteles II. Traduções de Vincenzo Cocco et al. São Paulo: Abril Cultural, 1979. p. 8-35. (Os Pensadores).

AUERBACH, Erich. Dante: poeta do mundo secular. Tradução por Raul de Sá Barbosa. Rio de Janeiro: Topbooks, 1997.

BAKHTIN, M ikhail. Questões de literatura e de estética: a teoria do romance. 2. ed. rev. aum. Traduzido por Aurora Fornoni Bernardini et al. São Paulo: Hucitec, 1990.

BIOGRAPHY. The New Encyclopaedia Britannica. 15. ed. Chicago: Encyclopaedia Britannica, 1990. 32 v. v. 2.

CARINO, Jonaedson. A biografia e sua instrumentalidade educativa. Educação \& Sociedade, Campinas, ano XX, n. 67, p. 153-181, ago. 1999. 
CHÂTELET François. El nacimiento da la historia: la formación del pensamiento historiador em Grécia. Madrid: Siglo XX de España, 1985.

CHÂTELET François. El nacimiento da la historia: la formación del pensamiento historiador em Grécia. Madrid: Siglo XX de España, 1985.

DETIENNE, Marcel. Os mestres da verdade na Grécia arcaica. Traduzido por Andréa Daher. Rio de Janeiro: Jorge Zahar, 1988.

HAVELOCK, Eric. A revolução da escrita na Grécia e suas conseqüências culturais. Traduzido por Ordep José Serra. Rio de Janeiro: Paz e Terra, 1996b.

HAVELOCK, Eric. Prefácio a Platão. Traduzido por Enid Abreu Dubránzsky. Campinas, SP: Papirus, 1996a.

ISER, Wolfgang. Os atos de fingir ou 0 que é fictício no texto ficcional. Traduzido por Heidrun Krieger Olinto e Luiz Costa Lima. In: COSTA LIMA, 1983, p. 384-416.

KRELL, David Farrell. Of M emory, Reminiscence and Writing: On the Verge. Bloomington: Indiana University Press, 1990.

LEROI-GOURHAN, André. 0 gesto e a palavra. Tradução por Vítor Gonçalves. Lisboa: Edições 70, 1985. 2v. v. 1 (Técnica e Linguagem).

MACHADO, Ana Maria. Como e por que ler os clássicos universais desde cedo? Rio de Janeiro: Objetiva, 2002.

VIDAL-NAQUET; Pierre. Prefácio. In: DETIENNE, 1988, p. 7-11. 